\title{
The risk of mental disorders in patients with disorders/differences of sex differentiation/development (DSD) and Y chromosome
}

\author{
Katarzyna Bajszczak¹, Maria Szarras-Czapnik², Renata Walczak-Jędrzejowska ${ }^{3}$, Katarzyna Marchlewska ${ }^{3}$, \\ Jolanta Słowikowska-Hilczer ${ }^{3}$
}

${ }^{1}$ Psychiatric Outpatient's Clinic for Children and Adolescents, Children's Memorial Health Institute, Warsaw, Poland

${ }^{2}$ Department of Endocrinology and Diabetology, Children's Memorial Health Institute, Warsaw, Poland

${ }^{3}$ Department of Andrology and Reproductive Endocrinology, Medical University, Lodz, Poland

\begin{abstract}
Introduction: Patients with disorders/differences of sex differentiation/development (DSD) are exposed to physical and mental suffering. The aim of the study was to assess the following: the mental health status and the risk of mental problems in adult DSD patients, their dependence on therapeutic procedures, and to identify groups of disorders that require particular psychological support.

Material and methods: The study involved 59 patients with DSD (gonadal dysgenesis — GD, androgen insensitivity syndrome - AIS, 5-alpha reductase deficiency, ovotestis), and with the $Y$ chromosome in the karyotype, aged 16-65 years. All completed the General Health Questionnaire (GHQ-28) for the assessment of their mental health status. Raw results were converted into sten scores using norms for the Polish adult population to assess the risk of mental problems.

Results: A high risk of mental problems was identified in $24 \%$ of individuals ( $26 \%$ men, $21 \%$ women). Women, when compared with men, displayed a significantly higher mean level of anxiety and insomnia (7.3 vs. 4.6 scores) and somatic symptoms (7.4 vs. 5.5), and worse general mental health status (25.6 vs. 18.8). The most disturbing symptoms were observed among patients with complete and partial AIS, and complete GD (general mental health status: 39.5, 24.3, and 24.2, respectively), women lacking a vagina (27.2), and without an enlarged clitoris (27.5). Patients after genital surgery had significantly fewer somatic symptoms (5.4 vs. 7.8; $\mathrm{p}<0.05)$ and better general mental health status in comparison to those without surgery (20.1 vs. 24.9; $\mathrm{p}<0.05)$. No significant differences were observed between patients using hormone replacement therapy and those who were not.

Conclusions: The individuals with DSD and Y chromosome in the karyotype have increased risk of developing mental problems in comparison to the general Polish population. The risk factors seem to be as follows: female gender, the lack of a vagina, the lack of virilisation (no enlarged clitoris), and no genital operations performed. In some cases, sex hormone replacement therapy may be also the risk of mental problems. Particularly vulnerable groups are CAIS, PAIS, and CGD. The psychological support and an individual approach to particular needs of these patients is necessary. (Endokrynol Pol 2020; 71 (2): 168-175)
\end{abstract}

Key words: mental health; somatic symptoms; hypogonadism; ambiguous genitalia; hormonal substitution; genital operations

\section{Introduction}

Human sexual differentiation is a complex process that takes place during the foetal period of life. Its disruption results in the occurrence of disorders/differences of sex differentiation/development (DSD). This term is used to describe a group of congenital defects manifested by abnormal gonads and/or genital anatomy. Disorders of sex differentiation are relatively rare, with a frequency of about 1:4500-5000 births [1, 2], but they are the cause of many diagnostic and therapeutic problems, as well as psychological problems of the patient and their family. Significantly more problems are observed in DSD patients with the $\mathrm{Y}$ chromosome, or its part, in the karyotype. The reason may be various congenital defects in male differentiation. One of them is a disorder in testicular differentiation such as: complete dysgenesis, where there are only streaks of connective tissue on both sides, partial dysgenesis, where testes are underdeveloped on both sides, asymmetric dysgenesis, where testis is on one side and connective tissue on the other, and the differentiation of the gonad into testis and ovary (ovotestis) in one or both sides. Other congenital defects such as androgen biosynthesis disorders, i.e. deficiency in 5-alpha reductase activity, an enzyme converting testosterone to the more active dihydrotestosterone, or insensitivity to androgens, where androgen activity can be absent in all or only

Prof. Jolanta Slowikowska-Hilczer, MD, PhD, Department of Andrology and Reproductive Endocrinology, Medical University of Lodz, Pomorska 251, 92-213 Lodz, Poland; e-mail: jolanta.slowikowska-hilczer@umed.lodz.pl 
some tissues, can also be the reason for DSD in individuals with $\mathrm{Y}$ chromosome. Usually serious abnormalities in the development of genitals are an indication for multistage genital surgery. Disorders that require many reconstructive operations cause greater physical and mental suffering $[3,4]$. Moreover, DSD patients with $\mathrm{Y}$ chromosome are at high risk of germ cell neoplastic lesions in the gonads, which is often an indication for gonadectomy [5]. Nordenskjöld et al. showed that psychological wellbeing is influenced by the type and severity of DSD, and this influence is observed in the long term [3].

Puberty is the most difficult period from the psychological point of view, when sexuality, sexual identity, and gender role, as well as sexual orientation, become highly important $[6,7]$. In many cases a diagnosis of DSD leads to anger, shame, and depression. A study of 86 patients with DSD aged 8-12 years from Germany, Austria, and Switzerland showed that pubertal children with these disorders tend to experience a worse quality of life [8]. A significant reduction in self-esteem, well-being, and functioning at school was observed. Similarly, although around half $(54.9 \%)$ of 51 children and adolescents with DSD studied in Turkey were not found to have a mental illness, the remaining $45.1 \%$ displayed depression, anxiety disorders, concentration disorders, and hyperactivity [9].

A significant problem faced by people with DSD is the lack of acceptance of their body dissimilarity and the associated shame, which typically leads to the avoidance of sexual contact and social exclusion. In particular, young people with DSD rarely develop close relationships with their peers $[10,11]$. Many teenagers with DSD experience puberty later than their peers or fail to spontaneously mature without sex hormone substitution. Differences in physical development and appearance, such as lack of breast development, lack of menstruation, lack of voice mutation, and lack of sexual hair, can cause stigmatisation, which significantly limits social relations.

The occurrence and severity of mental disorders can also be influenced by clinical management [12-15]. Firstly, the patient's right to intimacy is of great importance. This should be considered during examination, but also access to medical records, which often contain genital images, should be limited. The best possible mental state can be ensured by providing proper information on methods and consequences of the therapy, as well as providing psychological support adjusted to the age of the patient at each stage of treatment. According to the consensus of the American Lawson Wilkins Pediatric Endocrine Society (LWPES) and the European Society for Paediatric Endocrinology (ESPE), psychological support should be made available to both the patient with DSD and the family. The necessity of psychological support was even more clearly emphasised in the consensus update in $2016[16,17]$. Disorders of sex differentiation support groups may also be an important source of help.

The aim of the study was to assess the mental health status and the risk of mental disorders in adult patients with DSD and $Y$ chromosome in the Polish population, as well as the dependence of mental problems on therapeutic procedures, and to identify groups of disorders requiring particular psychological support.

\section{Material and methods}

The study was conducted among patients of the Endocrine Outpatients' Clinic of the Children's Memorial Health Institute in Warsaw and the Department of Andrology and Reproductive Endocrinology of the Medical University in Lodz, Poland. The study was approved by the Bioethics Committee of the Medical University in Lodz (no. RNN / 28/ 10 / KE).

\section{Study group}

The study inclusion criteria were the following: diagnosis of DSD $\mathrm{Y}$ chromosome in the karyotype, age $\geq 16$ years, and a recorded sex: either female (women) or male (men). Patients were recruited among persons in the intellectual norm (never diagnosed as intellectually disabled). About $72 \%$ had medium or higher education; however, the median age of participants was young, and several persons were still in the course of education.

The study included 59 patients ( 28 women and 31 men) aged 16-65 years (median 26 years). Among them four people reported gender dysphoria. The largest group was between 20 and 30 years old -28 patients $(47.5 \%)$, followed by the group under 20 years old - 18 patients $(30.5 \%)$, the next largest age group were patients over 40 years old - eight patients (13.5\%), and the least numerous group was from 30 to 40 years old - five patients (8.5\%). The subjects were patients with disorders such as complete (CGD), partial (PGD), and asymmetric gonadal dysgenesis (AGD), ovotestis, complete (CAIS) and partial androgen insensitivity syndrome (PAIS), and 5-alpha reductase deficiency (5-ARD). All presented disorders of male external genitalia differentiation.

Data regarding diagnosis, medical history, and applied therapies were obtained from available medical documentation. Each of the subjects underwent a medical examination.

The study group was divided by: 1) gender, 2) diagnosis, 3) clinical picture (disorders of genital development: men - micropenis (length $<7.5 \mathrm{~cm}$ ), hypospadias; women - virilisation mainly manifested as an enlarged clitoris), and 4) treatment methods (substitution with sex hormones, genital surgery). All examined men had the micropenis, and all except one patient presented severe hypospadias (perineal or scrotal). Among those who had undergone genital surgery procedures ( 34 subjects, $58 \%$ of all) 29 were men ( $94 \%$ of all men) and five were women ( $21 \%$ of all women). Hormonal substitution was received by 36 subjects ( $61 \%$ of all): 26 women ( $93 \%$ of all women) and 10 men ( $32 \%$ of all men). All subjects were under the care of an endocrinologist and claimed that they were taking the medicine as it had been prescribed. Some patients were diagnosed with hypertension, type 2 diabetes, dyslipidaemia osteopaenia, autoimmune disease, and gastric and eye problems. None of the diseases was serious.

The general characteristics of the subjects are presented in Table 1.

\section{Evaluation of mental health status}

The subjects completed the General Health Questionnaire (GHQ-28), which is used to assess mental health status in adults. The question- 
Table 1. Characteristics of the group of 59 patients with disorders of sex differentiation (DSD)

\begin{tabular}{|c|c|c|}
\hline \multicolumn{3}{|l|}{ Age (years) } \\
\hline Minimum-maximum & \multicolumn{2}{|c|}{$16-65$} \\
\hline Median & \multicolumn{2}{|c|}{23.0} \\
\hline Mean \pm SD & \multicolumn{2}{|c|}{$26.1 \pm 11.1$} \\
\hline \multicolumn{3}{|l|}{ Recorded sex (N) } \\
\hline Women & \multicolumn{2}{|c|}{28} \\
\hline Men & \multicolumn{2}{|c|}{31} \\
\hline Diagnosis (N) & Women & Men \\
\hline $\begin{array}{l}\text { Complete gonadal dysgenesis } \\
\text { (CGD) }\end{array}$ & 11 & 0 \\
\hline Partial gonadal dysgenesis (PGD) & 0 & 12 \\
\hline $\begin{array}{l}\text { Asymmetric gonadal dysgenesis } \\
\text { (AGD) }\end{array}$ & 2 & 11 \\
\hline $\begin{array}{l}\text { Complete androgen insensitivity } \\
\text { syndrome (CAIS) }\end{array}$ & 2 & 0 \\
\hline $\begin{array}{l}\text { Partial androgen insensitivity } \\
\text { syndrome (PAIS) }\end{array}$ & 13 & 6 \\
\hline Other (5-ARD, ovotestis) & 0 & 2 \\
\hline Clinical picture (N) & Women & Men \\
\hline Virilisation & 12 & - \\
\hline Without virilisation & 16 & - \\
\hline Vagina & 14 & - \\
\hline Without vagina & 14 & - \\
\hline Micropenis & - & 31 \\
\hline Normal penis & - & 0 \\
\hline Hypospadias & - & 30 \\
\hline Without hypospadias & - & 1 \\
\hline Treatment (N) & Women & Men \\
\hline Genital surgery & 6 & 29 \\
\hline Without genital surgery & 22 & 2 \\
\hline Hormonal substitution & 26 & 10 \\
\hline Without hormonal substitution & 2 & 21 \\
\hline
\end{tabular}

$\mathrm{N}$ - number of subjects; CGD — complete gonadal dysgenesis; $\mathrm{PGD}$ - partial gonadal dysgenesis; AGD — asymmetric gonadal dysgenesis; CAIS — complete androgen insensitivity syndrome; PAIS — partial androgen insensitivity syndrome; 5-ARD - 5-alpha reductase deficiency; SD - standard deviation

naire consists of 28 questions to assess the severity of: 1) somatic symptoms, 2) anxiety and insomnia, 3) disorders of daily functioning, and 4) symptoms of depression. The respondents chose one of four possible answers: better than usual, as usual, worse than usual, much worse than usual. The results were scored using a Likert scale (0-1-2-3). Each scale can be scored separately, giving a total score between 0 and 21 points for each scale, with a higher score indicating more disturbing symptoms. In addition, the sum of all points obtained on all four scales can be used as an assessment of the general mental health status, with a possible final result ranging from 0 to 84 points.

In order to determine statistically significant differences of mean test results, comparisons were made in the following groups: 1) gender, 2) diagnosis, 3) clinical picture, and 4) treatment. In this way it was possible to determine what parameters of GHQ-28 differ in those groups. In Table 2, letters $a$ or $b$ are marked in the compared pairs $(a-a, a 1-a 1, a 2-a 2, b-b)$ statistically significant at the level of $\mathrm{p}<0.05$ and $\mathrm{p}<0.01$.

The raw results for each scale and for the sum of the points obtained were converted into sten scores (from 1 to 10) using the norms for the Polish adult population included in the test manual [18]. The mean sten score in the nationwide population is 5.5 with a standard deviation of 2 . The risk of mental problems was determined to be high when the number of the sten scores was higher than that of the nationwide population.

\section{Statistical analysis}

Statistical analyses were performed using Statistica 10 software (StatSoft, Poland). The normality of the distribution of raw results was tested by the Shapiro-Wilk test. When comparing two independent samples, Student's t-test was used for the analysis of data with a normal distribution, while the Mann-Whitney U-test was used for abnormal distribution. Comparisons of more than two independent samples were carried out using ANOVA tests: ANOVA one-way for results with normal distribution, and the Kruskal-Wallis H-test for those with a non-normal distribution. The assumed level for all applied statistical tests was $\mathrm{p}<0.05$.

\section{Results}

The mean results of the GHQ-28 for the whole group and according to recorded sex, diagnosis, clinical picture, and treatment options are presented in Table 2. They show that DSD women compared with DSD men displayed a significantly higher average level of anxiety and insomnia (7.3 vs. 4.6 scores), more somatic symptoms ( 7.4 vs. 5.5 scores), and worse general mental health status (25.6 vs. 18.8 scores).

The most disturbing symptoms were observed especially among patients with PAIS and CGD: the mean overall score of the general mental health status was higher in these groups than in the whole group (24.3 and 24.2 vs. 22.1 scores) but not significantly. The result of the general mental health status in the CAIS patients was particularly high (39.5 scores); however, the group was very small, which does not allow us to draw reliable conclusions. Nevertheless, poor general mental health was also presented by women without a vagina and without virilisation, symptoms typical for CAIS women. A comparison of the mean test results with regard to the diagnosis revealed statistically significant differences between groups only in the mean level of somatic symptoms.

Taking into account the clinical picture, the most disturbing general mental health status was presented by women lacking a vagina (27.2 scores) and without an enlarged clitoris (without virilisation) (27.5 scores). The majority of disorders in daily functioning were reported by women without a vagina ( 8.4 scores). Anxiety and insomnia were mostly observed in women with a vagina (7.5 scores) and women without virilisation (8.0 scores). The least disturbing symptoms (general mental health status) were found among the men with 
Table 2. Mean raw scores obtained in the GHQ-28 test

\begin{tabular}{|c|c|c|c|c|c|c|}
\hline \multirow[t]{2}{*}{ Group } & \multirow[t]{2}{*}{$\mathbf{N}$} & $\begin{array}{l}\text { Somatic } \\
\text { symptoms }\end{array}$ & $\begin{array}{l}\text { Anxiety and } \\
\text { insomnia }\end{array}$ & $\begin{array}{l}\text { Disorders of daily } \\
\text { functioning }\end{array}$ & $\begin{array}{l}\text { Symptoms of } \\
\text { depression }\end{array}$ & $\begin{array}{c}\text { General mental } \\
\text { health status }\end{array}$ \\
\hline & & Mean \pm SD & Mean \pm SD & Mean \pm SD & Mean \pm SD & Mean \pm SD \\
\hline Total group & 59 & $6.39 \pm 3.7$ & $5.88 \pm 3.7$ & $6.97 \pm 2.3$ & $2.8 \pm 3.8$ & $22.1 \pm 9.9$ \\
\hline \multicolumn{7}{|l|}{ Recorded sex } \\
\hline Women & 28 & $7.4 \pm 3.8^{\mathrm{a}}$ & $7.3 \pm 3.9^{b}$ & $7.5 \pm 2.6$ & $3.4 \pm 3.6$ & $25.6 \pm 10.1^{b}$ \\
\hline Men & 31 & $5.5 \pm 3.4^{\mathrm{a}}$ & $4.6 \pm 3.0^{b}$ & $6.5 \pm 1.9$ & $2.3 \pm 4.1$ & $18.8 \pm 8.7^{b}$ \\
\hline \multicolumn{7}{|l|}{ Diagnosis } \\
\hline CGD & 11 & $7.6 \pm 3.7^{\mathrm{a}}$ & $7.6 \pm 4.0$ & $6.5 \pm 2.3$ & $2.6 \pm 2.3$ & $24.2 \pm 7.4$ \\
\hline PGD & 12 & $5.3 \pm 3.5^{\mathrm{a} 1}$ & $4.5 \pm 3.7$ & $6.2 \pm 1.8$ & $2.2 \pm 4.7$ & $18.1 \pm 8.1$ \\
\hline AGD & 13 & $4.4 \pm 2.4^{\mathrm{a}, \mathrm{a} 2, \mathrm{~b}}$ & $4.4 \pm 2.6$ & $6.6 \pm 2.4$ & $2.5 \pm 3.9$ & $17.9 \pm 8.9$ \\
\hline CAIS & 2 & $11.5 \pm 9.2^{\mathrm{a} 1, \mathrm{~b}}$ & $7.5 \pm 2.1$ & $10.0 \pm 1.4$ & $10.5 \pm 2.1$ & $39.5 \pm 14.9$ \\
\hline PAIS & 19 & $7.0 \pm 3.4^{\mathrm{a} 2}$ & $6.5 \pm 4.1$ & $7.7 \pm 2.3$ & $2.9 \pm 3.6$ & $24.3 \pm 10.7$ \\
\hline Other (5-ARD, ovotestis) & 2 & $8.5 \pm 3.5$ & $7.0 \pm 1.4$ & $6.5 \pm 0.7$ & 1.0 & $23.0 \pm 2.8$ \\
\hline \multicolumn{7}{|l|}{ Clinical picture } \\
\hline Women with vagina & 14 & $7.2 \pm 3.4$ & $7.5 \pm 3.7$ & $6.6 \pm 2.9$ & $2.7 \pm 2.3$ & $24.0 \pm 7.8$ \\
\hline Women without vagina & 14 & $7.6 \pm 4.2$ & $7.1 \pm 4.2$ & $8.4 \pm 1.9^{\mathrm{a} 1}$ & $4.0 \pm 4.5$ & $27.2 \pm 11.9^{\mathrm{a}}$ \\
\hline Women with virilisation & 12 & $6.1 \pm 2.2$ & $6.3 \pm 3.9$ & $7.8 \pm 2.7^{\mathrm{a}}$ & $2.8 \pm 3.5$ & $23.1 \pm 8.8$ \\
\hline Women without virilisation & 16 & $8.4 \pm 4.4$ & $8.0 \pm 3.9^{\mathrm{a}}$ & $7.2 \pm 2.6$ & $3.8 \pm 3.6$ & $27.5 \pm 10.8^{b}$ \\
\hline Men with micropenis & 31 & $5.5 \pm 3.4$ & $4.6 \pm 3.0^{\mathrm{a}}$ & $6.5 \pm 1.9^{\mathrm{a}, \mathrm{a} 1}$ & $2.3 \pm 4.0$ & $18.8 \pm 8.7^{\mathrm{a}, \mathrm{b}}$ \\
\hline Men with hypospadias & 30 & $5.2 \pm 3.3$ & $4.6 \pm 3.1$ & $6.5 \pm 1.9$ & $2.3 \pm 4.1$ & $18.6 \pm 8.8$ \\
\hline \multicolumn{7}{|l|}{ Treatment } \\
\hline Genital surgery & 35 & $5.4 \pm 3.2^{\mathrm{a}}$ & $5.2 \pm 3.4$ & $6.7 \pm 2.3$ & $2.7 \pm 4.2$ & $20.1 \pm 9.6^{\mathrm{a}}$ \\
\hline Without genital surgery & 24 & $7.8 \pm 3.9^{\mathrm{a}}$ & $6.9 \pm 4.0$ & $7.4 \pm 2.2$ & $2.9 \pm 3.3$ & $24.9 \pm 9.8^{\mathrm{a}}$ \\
\hline Hormonal substitution & 36 & $7.1 \pm 3.7$ & $6.5 \pm 3.9$ & $7.2 \pm 2.4$ & $2.7 \pm 3.4$ & $23.6 \pm 10.0$ \\
\hline $\begin{array}{l}\text { Without hormonal } \\
\text { substitution }\end{array}$ & 23 & $5.4 \pm 3.6$ & $4.9 \pm 3.2$ & $6.6 \pm 2.1$ & $2.9 \pm 4.5$ & $19.6 \pm 9.4$ \\
\hline
\end{tabular}

a, a1, a2 differences between averages of compared pairs (a-a, a1-a1, a2-a2) in individual groups significant at the level of $p<0.05$; ${ }^{b}$ differences between the mean of compared pairs $(b-b)$ in particular groups significant at $p<0.01$

$\mathrm{N}$ - number of subjects; CGD — complete gonadal dysgenesis; PGD — partial gonadal dysgenesis; AGD — asymmetric gonadal dysgenesis; CAIS — complete androgen insensitivity syndrome; PAIS — partial androgen insensitivity syndrome; 5-ARD — 5-alpha reductase deficiency; SD — standard deviation

micropenis (18.8 scores) and hypospadias (18.6 scores). Statistically significantly higher level of functional disorders was shown by the women without a vagina and the women with virilisation than the men with micropenis (8.4 vs. 6.5 and 7.8 vs. 6.5 scores, respectively; $\mathrm{p}<0.05)$. Disorders of sex differentiation women without virilisation presented significantly worse general mental health status than DSD men with micropenis (27.5 vs. 18.8 scores; $\mathrm{p}<0.01$ ) and reported also the significantly higher levels of anxiety and insomnia (8.0 vs. 4.6 scores; $\mathrm{p}<0.05)$.

Analysis of the examined groups depending on the applied therapies showed that patients after genital surgery had significantly fewer somatic symptoms (5.4 vs. 7.8; $\mathrm{p}<0.05$ ) and better general mental health status in comparison to the patients without surgery (20.1 vs. 24.9; p < 0.05). No significant differences were observed between patients using hormone replacement therapy and those who were not; however, patients with hormonal substitution presented worse general mental health status (23.6 vs. 19.6).

An analysis of the risk of mental problems with regard to the recorded sex, diagnosis, clinical picture, and treatment in comparison to the Polish nationwide population is presented in Table 3. A high risk (7-10 stens), i.e. higher than in the nationwide population, was found in 14 subjects $(24 \%)$, while a moderate (5-6 stens), i.e. similar to that observed in the nationwide population, in 27 subjects $(46 \%)$. With regard to the recorded sex, it was found that $26 \%$ of men and $21 \%$ of women had higher risk of mental problems than the general Polish population.

The analysis of the results with regard to the diagnosis showed that the highest number of DSD patients had low or medium risk of mental problems. High risk was found in $25 \%$ of patients with PGD and AGD, as 
Table 3. Percentage distribution of disorders of sex differentiation (DSD) subjects with different levels of mental problems risk assessed by the GHQ-28 test scores converted to sten scores using the norms for the Polish adult population

\begin{tabular}{|c|c|c|c|}
\hline Group & $\begin{array}{c}\text { Low risk } \\
1-4 \text { stens (\%) }\end{array}$ & $\begin{array}{c}\text { Medium risk } \\
5-6 \text { stens }(\%)\end{array}$ & $\begin{array}{c}\text { High risk } \\
\text { 7-10 stens (\%) }\end{array}$ \\
\hline Total group & 30 & 46 & 24 \\
\hline \multicolumn{4}{|l|}{ Recorded sex } \\
\hline Women & 29 & 50 & 21 \\
\hline Men & 32 & 42 & 26 \\
\hline \multicolumn{4}{|l|}{ Diagnosis } \\
\hline TGD & 27 & 55 & 18 \\
\hline PGD & 33 & 42 & 25 \\
\hline AGD & 38 & 38 & 24 \\
\hline CAIS & 0 & 50 & 50 \\
\hline PAIS & 32 & 47 & 21 \\
\hline Other (5-ARD, ovotestis) & 0 & 50 & 50 \\
\hline \multicolumn{4}{|l|}{ Clinical picture } \\
\hline Women with vagina & 29 & 50 & 21 \\
\hline Women without vagina & 29 & 50 & 21 \\
\hline Women with virilisation & 33 & 50 & 17 \\
\hline Women without virilisation & 25 & 50 & 25 \\
\hline Men with micropenis & 3 & 42 & 26 \\
\hline Men with hypospadias & 33 & 43 & 24 \\
\hline \multicolumn{4}{|l|}{ Treatment } \\
\hline Genital surgery & 34 & 40 & 26 \\
\hline Without genital surgery & 25 & 54 & 21 \\
\hline Hormonal substitution & 31 & 44 & 25 \\
\hline Without hormonal substitution & 30 & 48 & 22 \\
\hline
\end{tabular}

TGD — total gonadal dysgenesis; CGD — complete gonadal dysgenesis; PGD — partial gonadal dysgenesis; AGD — asymmetric gonadal dysgenesis;

CAIS — complete androgen insensitivity syndrome; PAIS — partial androgen insensitivity syndrome; 5-ARD — 5-alpha reductase deficiency

well as in 50\% of the subjects from the smallest groups: CAIS and "other".

Regarding the clinical picture, the risk of mental problems was most frequently found to be the same as in the general Polish population. High risk was identified in $25 \%$ of DSD women without virilisation and $26 \%$ of DSD men with micropenis. With regard to the applied treatment, it was found that most frequently the patients after genital surgery $(26 \%)$ and the patients with hormonal therapy $(25 \%)$ had high risk of mental problems, i.e. higher than the general Polish population.

\section{Discussion}

In the presented study, every fourth respondent was found to demonstrate a higher risk of mental problems than the nationwide Polish population. Of the four types of symptoms examined in GHQ-28, the most disturbing were the daily functioning disorders and somatic symptoms. The high risk of mental problems means the presence of suicidal thoughts and risk of their realisation, higher than in the general Polish population. For comparison, in the dsd-LIFE study conducted in 14 centres in six European countries, including two centres in Poland, the mental health status was assessed in 1022 persons with various forms of DSD [19]. Almost 20\% of participants sometimes or often had suicidal thoughts, almost 7\% had attempted suicide, and 27\% reported chronic psychiatric problems, while in the general European population the suicidal thoughts rate is $9.2 \%$ and the suicidal attempt rate is $2.7 \%$. Mental problems were observed predominantly among men with Klinefelter syndrome, but also in men with 46,XY DSD [19, 20]. Johannsen et al. [4] also reported an increased incidence of mental problems in adult DSD patients. In turn, over half $(55 \%)$ of a group of children with various causes of DSD studied in Turkey were found to have no psychiatric symptoms, but $12 \%$ had mood disorders and 6\% had anxiety disorders [8]. In contrast, a study conducted in China failed to find any significant differences in the 
social functioning of persons with DSD compared to the general population [22]. However, the authors indicate that those with DSD tended to display a poorer mental health status compared to the general population.

The risk of mental problems may depend on the culture and social group, in which DSD persons live. Different social and cultural groups have variable expectations and definitions of masculinity and femininity, which define appropriate behaviours, personality attributes, and social roles. The way DSD is viewed and managed in different cultures varies widely. Warne and Raza [23] suggest that DSD is such a complex condition that even well-educated people find it difficult to understand. When families are very poor and lacking in basic education, and the health system is starved of resources, traditional beliefs, folk remedies, and prejudice combine to make the lives of children and adults with DSD extremely difficult. Stigmatisation, isolation, and withdrawal from social interaction may be stressful and may lead to mental problems [24].

It might be supposed also that the level of intelligence is associated with the level of potential psychic illness risk. However, Barchmann and Kinze [25] found out that only $6 \%$ of the patients from a child psychiatric population had IQ over 120. The authors observed that with higher intelligence are found better performances of concentration, more reflexive style of study, better school notes, and more favourable motor capabilities, but also less pronounced signs of anxiety and neuroticism, as well as a poorer social adaptation and less favourable effects of treatment. In our study most of the participants had medium or higher education and nobody was diagnosed as mentally retarded; however, we did not assess the IQ of the DSD patientsDisorders of sex differentiation are usually considered as quite severe diseases, with many health complications such as hypogonadism, infertility, poor sexual function, and possibly other disorders not related to DSD. All of these problems have been confirmed by dsd-LIFE study [20, 26-28]. However, the dsd-LIFE study revealed that fair to very good general health was reported by $91.4 \%$ of DSD subjects, and only $8.6 \%$ reported bad/very bad general health, while in the general European population it is, respectively, $94.0 \%$ and $6.0 \%$. Longstanding health issues other than DSD and feeling limited in daily life were reported in $51.0 \%$ and $38.6 \%$, respectively (controls $24.5 \%$ and $13.8 \%$ ). A disorder other than DSD was present in $84.3 \%$, while in controls it was $24.6 \%$. In all DSD subgroups Klinefelter and Turner patients reported comorbidities the most frequently $(94.5 \%$ and $87.1 \%$, respectively), while $46, \mathrm{XY}$ DSD patients less often $(75 \%)$. There are not many studies showing a comparison of mental health status between DSD and other severe diseases. For example, Warne et al.
[29] argue that no significant differences exist between people with DSD and age-matched adults with insulin dependent diabetes mellitus in terms of physical and mental health or the occurrence of depression or anxiety symptoms.

In the presented study, worse results were obtained by the women than by the men. The women with DSD had significantly more somatic symptoms, more symptoms of anxiety and insomnia, and their overall mental health was worse than that of the men with DSD. These findings indicate that DSD women may require psychological and psychiatric support more often than DSD men. Similar observations were made in a Brazilian study on the quality of life of adults with DSD [30]. In addition, a study conducted in Italy found that almost one third of women with DSD declared using psychiatric drugs [21], which is higher than in the general population, in which psychiatric treatment is used by $12 \%$ of Italian women. Wisniewski and Mazur [31] claim that all 46,XY DSD conditions are under-studied. They suggest that in order to improve the quality of life of DSD persons more attention should be devoted to the study of their mental and general health, cognitive abilities, fertility, and sexual function.

Among the subjects examined in the presented study, the worst overall mental health status was demonstrated in the patients with CAIS, PAIS, and CGD. The women with CAIS had the highest severity of symptoms in all scales of the GHQ-28. These women are characterised by a male karyotype $(46, \mathrm{XY})$, female gender identity, female body proportions, female external genitalia, lack of vaginal development (short, blindly ended), lack of or very weak pubic hair, presence of testicles in the abdomen or the upper part of inguinal canal, and infertility. Although CAIS does not provide symptoms at first glance, patients with this disorder may experience reduced mood and low self-esteem, and reveal uncertainty in sexual contact because of the awareness of having a male karyotype and testicles [32]. In another study, almost every woman with CAIS admitted that at some point in her life she needed psychological help [33]. Minto et al. [34] indicate that infertility, in particular, causes mental problems in CAIS women, because they feel worse than other women.

Although none of the diagnostic groups in the present study displayed psychiatric disorders as serious as those reported by the women with CAIS, other studies have noted much more serious psychological consequences in the case of PAIS. Both men and women with this diagnosis have reported mental problems, suicidal tendencies, and suicide attempts [32, 35, 36]. In patients with 5-ARD, increased mental distress and suicidal thoughts were also observed, especially in patients raised as women [32]. 
In the presented study, more than one half of the subjects $(58 \%)$ had undergone at least one genital surgery procedure: almost all men (94\%) and every fifth woman $(21 \%)$. These procedures are used less frequently in Poland than in other countries. For comparison, a German study by Jürgensen et al. [37] found $90 \%$ of DSD adolescents and $87 \%$ of DSD adults to have undergone at least one operation associated with DSD. Patients without surgical correction of reproductive organs reported more worrying somatic symptoms, and their overall mental health status was worse than patients after surgery, demonstrating the positive effect of plastic genital surgery on the mental health of persons with DSD. Other studies also have shown that well-performed corrective surgery has a positive effect on mental health status [38]. However, in a German study, where patients with 46,XY DSD were examined after genital surgery, almost half $(47 \%)$ were not satisfied with the effects of the operation, and $37 \%$ reported dissatisfaction with the quality of sexual life. Therefore, in recent years, many specialists suggest limiting the number of surgical operations performed on genital organs in DSD patients, especially in younger children [39]. It might be suggested that with the increasing number of surgical operations the mental health status is becoming worse. Unfortunately, we were not able to check this in our group of DSD patients because of the missing medical documentation, especially from childhood.

It has been shown also that well-planned and conducted hormonal replacement therapy may have a positive influence on well-being [38]. However, in our study, DSD patients using substitution with sex hormones presented the worse general mental health status in comparison to those who were not, but not significantly. Patients with a high risk of mental problems were identified more frequently in the group using sex hormone therapy. In other studies, it was demonstrated that the lack of gonads, which is associated with a deficiency of sex steroids (hypogonadism) and hence a lack of secondary sexual characteristic development requiring hormonal substitution, may cause not only low self-esteem and shame, but also negatively affect the sexual life of adult patients [39]. The development of mental health problems has been attributed to improperly carried out hormonal substitution: poorly selected hormonal preparation, incorrect dose, unsatisfactory route of administration, and side effects. In a large dsd-LIFE clinical trial, in which 1040 adults with DSD participated, 20\% of those receiving hormone replacement were dissatisfied with it, mostly due to adverse effects on mood [26, 27]. The authors suggest providing accurate information to patients about the use of this therapy, as well as individually adapting the course of therapy to the patient's expectations.

The number of DSD patients studied here is not large but is sufficient to preliminarily indicate some problems that are causes of psychic suffering. Their problems may be various in different ages, and so further monitoring of patients should be carried out. It is also necessary to confirm these observations on a larger group of patients in different age ranges.

\section{Conclusions}

The individuals with DSD and Y chromosome in the karyotype have increased risk of developing mental problems in comparison to the general Polish population. The risk factors seem to be: female gender, the lack of a vagina, the lack of virilisation (no enlarged clitoris), and no genital operations performed. In some cases, sex hormone replacement therapy may also pose a risk of mental problems. Particularly vulnerable groups are CAIS, PAIS, and CGD. Psychological support and an individual approach to the particular needs of these patients is necessary.

\section{Acknowledgements}

The authors thank Mr. Edward Lowczowski from the Centre for the Teaching of Foreign Languages, Medical University of Lodz, for checking and improving the English language in the article.

\section{Conflicts of interest}

The authors do not disclose any conflicts of interest.

\section{Funding}

The study was funded by the Polish Ministry of Science, grant no. N N407 277339 and the Medical University of Lodz, grant no. 503/1-089-03/503-01.

\section{Authors' contributions}

K.B. - conception, design, investigations, analysis of data, writing of the manuscript; M.S.C. - conception, design, investigations, review of the manuscript; R.W.J. - investigations, review; K.M. - statistical analysis; J.S.H. - conception, design, investigations, analysis of data, review, supervision.

\section{References}

1. Thyen U, Lanz K, Holterhus PM, et al. Epidemiology and initial management of ambiguous genitalia at birth in Germany. Horm Res. 2006; 66(4): 195-203, doi: 10.1159/000094782, indexed in Pubmed: 16877870.

2. Öçal G. Current concepts in disorders of sexual development. J Clin Res Pediatr Endocrinol. 2011; 3(3): 105-114, doi: 10.4274/jcrpe.v3i3.22, indexed in Pubmed: 21911322.

3. Nordenskjöld A, Holmdahl G, Frisén L, et al. Type of mutation and surgical procedure affect long-term quality of life for women with congenital adrenal hyperplasia. J Clin Endocrinol Metab. 2008; 93(2): 380-386, doi: 10.1210/jc.2007-0556, indexed in Pubmed: 18029470. 
4. Johannsen TH, Ripa CPL, Mortensen EL, et al. Quality of life in 70 women with disorders of sex development. Eur J Endocrinol. 2006; 155(6): 877-885, doi: 10.1530/eje.1.02294, indexed in Pubmed: 17132758

5. Liu AX, Shi HY, Cai ZJ, et al. Increased risk of gonadal malignancy and prophylactic gonadectomy: a study of 102 phenotypic female patients with Y chromosome or Y-derived sequences. Hum Reprod. 2014; 29(7): 1413-1419, doi: 10.1093/humrep/deu109, indexed in Pubmed: 24826988.

6. Wisniewski AB, Migeon CJ. Gender identity/role differentiation in adolescents affected by syndromes of abnormal sex differentiation. Adolesc Med. 2002; 13(1): 119-28, vii, indexed in Pubmed: 11841959.

7. Bajszczak K, Słowikowska-Hilczer J. [Therapeutic problems in disorders of sex development]. Pediatr Endocrinol Diabetes Metab. 2016; 22(1) 26-31, doi: 10.18544/PEDM-22.01.0047, indexed in Pubmed: 28132070.

8. Jürgensen M, Lux A, Wien SB, et al. Health-related quality of life in children with disorders of sex development (DSD). Europ J Pediatr. 2014; 173: 893-903, doi: 10.1007/s00431-014-2264-z, indexed in Pubmed: 24469231.

9. Özbaran B, Özen S, Gökșen D, et al. Psychiatric approaches for disorder of sex development: experience of a multidisciplinary team. J Clin Res Pediatr Endocrinol. 2013; 5(4): 229-235, doi: 10.4274/Jcrpe.1044, indexed in Pubmed: 24379031.

10. Kleinemeier E, Jurgensen M, Lux A, et al. Psychological adjustment and sexual development of adolescents with disorders of sex development. J Adolesc Health. 2010; 47: 463-471, doi: 10.1016/j.jadohealth.2010.03.007, indexed in Pubmed: 20970081.

11. Patton GC, Viner R. Pubertal transitions in health. Lancet. 2007; 369(9567): 1130-1139, doi: 10.1016/S0140-6736(07)60366-3, indexed in Pubmed: 17398312.

12. Money J, Ogunro C. Behavioral sexology: ten cases of genetic male intersexuality with impaired prenatal and pubertal androgenization. Arch Sex Behav. 1974; 3(3): 181-205, doi: 10.1007/bf01541485, indexed in Pubmed: 4836840.

13. Vates TS, Fleming P, Leleszi JP, et al. Functional, social and psychosexua adjustment after vaginal reconstruction. J Urol. 1999; 162(1): 182-187, doi: 10.1097/00005392-199907000-00065, indexed in Pubmed: 10379784.

14. Bajszczak K, Szarras-Czapnik M, Slowikowska-Hilczer J. Sex development disorders - new nomenclature and guidelines in therapeutic treatment. Pol Sexol. 2014; 12(2): 74-80.

15. Migeon CJ, Wisniewski AB, Gearhart JP, et al. Ambiguous genitalia with perineoscrotal hypospadias in 46,XY individuals: long-term medical, surgical, and psychosexual outcome. Pediatrics. 2002; 110(3): e31 doi: 10.1542/peds.110.3.e31, indexed in Pubmed: 12205281.

16. Lee PA, Houk CP, Ahmed SF, et al. International Consensus Conference on Intersex organized by the Lawson Wilkins Pediatric Endocrine Society and the European Society for Paediatric Endocrinology. Consensus statement on management of intersex disorders. International Consensus Conference on Intersex. Pediatrics. 2006; 118(2): e488-e500, doi: 10.1542/peds.2006-0738, indexed in Pubmed: 16882788.

17. Lee PA, Nordenström A, Houk CP, et al. Global DSD Update Consortium. Global Disorders of Sex Development Update since 2006: Perceptions, Approach and Care. Horm Res Paediatr. 2016; 85(3): 158-180, doi: 10.1159/000442975, indexed in Pubmed: 26820577.

18. Goldberg D. Manual for users of GHQ-12 and GHQ-28 questionnaires. Polish adaptation. Prof. J. Nofer Institute of Occupational Medicine, Lodz 2001.

19. de Vries ALC, Roehle R, Marshall L, et al dsd-LIFE Group. Menta Health of a Large Group of Adults With Disorders of Sex Development in Six European Countries. Psychosom Med. 2019; 81(7): 629-640 doi: 10.1097/PSY.0000000000000718, indexed in Pubmed: 31232913.

20. Falhammar H, Claahsen-van der Grinten H, Reisch N, et al. dsd-LIFE group. Health status in 1040 adults with disorders of sex development (DSD): a European multicenter study. Endocr Connect. 2018; 7(3): 466-478, doi: 10.1530/EC-18-0031, indexed in Pubmed: 29490934.

21. D'Alberton F, Assante MT, Foresti M, et al. Quality of Life and Psychological Adjustment of Women Living with 46,XY Differences of Sex Development. J Sex Med. 2015; 12(6): 1440-1449, doi: 10.1111/jsm.12884, indexed in Pubmed: 25893774

22. Wang C, Tian $Q$. The investigation of quality of life in 87 Chinese patients with disorders of sex development. Biomed Res Int. 2015; 2015: 342420, doi: 10.1155/2015/342420, indexed in Pubmed: 26075230.

23. Warne GL, Raza J. Disorders of sex development (DSDs), their presentation and management in different cultures. Rev Endocr Metab
Disord. 2008; 9(3): 227-236, doi: 10.1007/s11154-008-9084-2, indexed in Pubmed: 18633712

24. Ediati A, Juniarto AZ, Birnie E, et al. Social stigmatisation in late identified patients with disorders of sex development in Indonesia. BMJ Paediat Open. 2017; 1(1): e000130, doi: 10.1136/bmjpo-2017-000130, indexed in Pubmed: 29637149.

25. Barchmann $\mathrm{H}$, Kinze W. Behaviour and achievement disorders in children with high intelligence. Acta Paedopsychiatr. 1990; 53(2): 168-172, indexed in Pubmed: 2178309.

26. Nordenström A, Röhle R, Thyen U, et al. dsd-LIFE group. Hormone therapy and patient satisfaction with treatment, in a large cohort of diverse disorders of sex development. Clin Endocrinol (Oxf). 2018; 88(3): 397-408, doi: 10.1111/cen.13518, indexed in Pubmed: 29149458.

27. Słowikowska-Hilczer J, Hirschberg AL, Claahsen-van der Grinten $\mathrm{H}_{\text {, }}$ et al. dsd-LIFE Group. Fertility outcome and information on fertility issues in individuals with different forms of disorders of sex development: findings from the dsd-LIFE study. Fertil Steril. 2017; 108(5): 822-831, doi: 10.1016/j.fertnstert.2017.08.013, indexed in Pubmed: 28923284 .

28. Kreukels BPC, Cohen-Kettenis PT, Roehle R, et al. Sexuality in Adults with Differences/Disorders of Sex Development (DSD): Findings from the dsd-LIFE Study. J Sex Marital Ther. 2019; 45(8): 688-705, doi: 10.108 0/0092623X.2019.1610123, indexed in Pubmed: 31034334.

29. Warne G, Grover S, Hutson J, et al. Murdoch Childrens Research Institute Sex Study Group. A long-term outcome study of intersex conditions. J Pediatr Endocrinol Metab. 2005; 18(6): 555-567, doi: 10.1515/jpem.2005.18.6.555, indexed in Pubmed: 16042323

30. Amaral RC, Inacio M, Brito VN, et al. Quality of life of patients with 46,XX and 46,XY disorders of sex development. Clin Endocrinol (Oxf). 2015; 82(2): 159-164, doi: 10.1111/cen.12561, indexed in Pubmed 25040878 .

31. Wisniewski AB, Mazur T. 46,XY DSD with Female or Ambiguous External Genitalia at Birth due to Androgen Insensitivity Syndrome, 5alpha-Reductase-2 Deficiency, or 17beta-Hydroxysteroid Dehydrogenase Deficiency: A Review of Quality of Life Outcomes. Int J Pediat Endocrinol. 2009; 2009: 567430, doi: 10.1155/2009/567430, indexed in Pubmed: 19956704.

32. Schützmann $\mathrm{K}$, Brinkmann $\mathrm{L}$, Schacht $\mathrm{M}$, et al. Psychological distress, self-harming behavior, and suicidal tendencies in adults with disorders of sex development. Arch Sex Behav. 2009; 38(1): 16-33, doi: 10.1007/s10508-007-9241-9, indexed in Pubmed: 17943433.

33. Wisniewski AB, Migeon CJ, Meyer-Bahlburg HF, et al. Complete androgen insensitivity syndrome: long-term medical, surgical, and psychosexual outcome. J Clin Endocrinol Metab. 2000; 85(8): 2664-2669 doi: 10.1210/jcem.85.8.6742, indexed in Pubmed: 10946863.

34. Minto CL, Liao KLM, Conway GS, et al. Sexual function in women with complete androgen insensitivity syndrome. Fertil Steril. 2003; 80(1): 157-164, doi: 10.1016/s0015-0282(03)00501-6, indexed in Pubmed: 12849818

35. Hines M, Ahmed SF, Hughes IA. Psychological outcomes and gender-related development in complete androgen insensitivity syndrome. Arch Sex Behav. 2003; 32(2): 93-101, doi: 10.1023/a:1022492106974, indexed in Pubmed: 12710824

36. Diamond M, Watson LA. Androgen insensitivity syndrome and Klinefelter's syndrome: sex and gender considerations. Child Adolesc Psychiat Clin N Am. 2004; 13(3): 623-40, viii, doi: 10.1016/j.chc.2004.02.015, indexed in Pubmed: 15183377.

37. Jürgensen M, Kleinemeier E, Lux A, et al. DSD Network Working Group DSD Network Working Group. Psychosexual development in children with disorder of sex development (DSD)--results from the German Clinical Evaluation Study. J Pediatr Endocrinol Metab. 2010; 23(6): 565-578, doi: 10.1515/jpem.2010.095, indexed in Pubmed: 20662330.

38. Gupta DK, Shilpa S, Amini AC, et al. Congenital adrenal hyperplasia: long-term evaluation of feminizing genitoplasty and psychosocial aspects. Pediatr Surg Int. 2006; 22(11): 905-909, doi: 10.1007/s00383-006-1765-x, indexed in Pubmed: 16947028.

39. Köhler B, Kleinemeier E, Lux A, et al. DSD Network Working Group. Satisfaction with genital surgery and sexual life of adults with XY disorders of sex development: results from the German clinical evaluation study. J Clin Endocrinol Metab. 2012; 97(2): 577-588, doi: 10.1210/jc.2011-1441, indexed in Pubmed: 22090272. 